\title{
Zoning Planning for Sustainable Development and Exploitation of the Mountainous Areas
}

\author{
Vasileios C. Drosos, Sarantis - Angelos G. Liampas, and Dimitrios E. Farmakis
}

\begin{abstract}
The trends of abandonment of mountainous areas for coastal and urban areas and depopulation are considered as additional effects of urbanization and the dominance of tertiary sector activities in Greece.

The basic target of this paper is the specification of strategic directions to an integrated development of the mountainous areas through global measures of zoning policies and proposals of specialized productive activities, according to a proper typology that characterises the differentiation of regional problems, needs and perspectives of those areas.

In this direction, certain measures of Land Policy for the Integrated Development of mountainous areas, which aim to maximize the potential of these areas in the fields of agriculture, stockbreeding and forestry, are proposed.

The study finally sets some strategic directions for integrated development of mountainous areas through a specific spatial planning, protected natural environment and the establishment of new management bodies for mountainous areas.
\end{abstract}

Index Terms-Transportation system, infrastructure system, integrated developments.

\section{INTRODUCTION}

The development of mountainous areas is correlated with the development of human impact on them, since any kind of economical development is usually also characterized by unfavorable environmental impacts. However, there is an inherent paradox, namely this human impact degrades the natural and built-up environment, which simultaneously comprises human's raw material for his development.

In the late 70's the development planning has turned from peripheral to regional level in order to emphasize the regional problem also on the regional planning, according to the range of the regional productive potentialities and its interface with the peripheral market.

Every regional developmental program (RDP) has to face the particularity of the developmental features of the region which is to be parleyed. Therefore, no technical prerequisite is able to guarantee the propriety of the diagnosis or the developmental prospective and interventions suggested [1].

Regional development assessments specified on mountainous areas are scarce and rarely completed in the framework of zoning which is able to obtain the vital space with the help of an organic and flexible plan about the land uses [2].

During the past years and after the turnouts of dramatic

Manuscript received November 30, 2014; revised February 28, 2015.

The authors are with the Department of Forestry and Management of the Environment and Natural Resources, Democritus University of Thrace, Orestiada, $68200 \quad$ Greece (e-mail: vdrosos@fmenr.duth.gr, angel40das@yahoo.gr, 492603@gmail.com). significance for humanity which occurred due to the reckless and catastrophic for the environment linear economical "developmental" activity, the perception that development is either complete, namely economical, social, technical/technological, political, and cultural, in harmonious interaction and respect of the natural and cultural environment, whose part is also humankind, or nothing, is becoming more popular, directly or indirectly [3], [4].

Unfortunately however, even in cases where the term of the Integrated Development on schemes and programs is used (e.g. Integrated Development of the rural regions), the compulsive necessity of the harmonious collaboration amongst the newest scientific and technological potentialities from one side and the virtual potentialities and restrictions of the physical and socioeconomic reality on local, peripheral, national and global level has not yet been fully understood. The strategies for "development" that are being applied, as we can also see from the strategy applied on the fields of agriculture, stockbreeding and forestry, having as "standard" (or pretext) the sustainable development, which is a development with ambiguous as well as documented dubious context [5], [6], encourage in fact the classical sectorial/departmental development, targeting on the further development of competitiveness and the financial magnification, serving mainly the interests of Northwest Europe.

The integrated development can only be achieved after thorough and inter-scientific approach, analysis, record, observation and utilization of the real efficacy and potentiality of the respective physical and socioeconomic reality as these are related with each other, they are interdependent and interactive [7], [8]. This approach and methodology should be followed on developmental planning.

Specifically for the particularly vulnerable and sensitive mountainous regions, integrated development is not only a necessity but also an obtainable target. The perception of a unified approach of the sectors of agriculture, stockbreeding and forestry has emerged due to decrees and decisions made by EU during the past years. While in theory the interactive relationship and the interdependence on many levels of these sectors is acknowledged, in practice all the measures are taken still mainly sectorial and sporadic.

The systematic concentration, survey, observation, analysis and interpretation of the essential credible, diachronic and continuously updated of all information regarding the specific physical and socioeconomic reality of the mountainous areas and the conditions of the Greek agriculture, stockbreeding and forestry, are a prerequisite for setting up a complete landing strategy on the fields of agriculture, stockbreeding and forestry. 
A prerequisite for developing a comprehensive land policy in agriculture, livestock and forestry, is the systematic collection, mapping, monitoring, analysis and interpretation of the necessary reliable, timeless and continually updated data on the specific physical and socio-economic realities of mountain regions and state of Greek agriculture, livestock and forestry.

The objective of this study is the specification of strategic directions for an integrated development of mountainous areas through global measures in relation to zoning policies and also proposals regarding specialized production activities, according to a proper typology that characterises the differentiation of regional problems, needs and perspectives.

\section{MATERIALS AND METHODS}

\section{A. Detecting Problems and Evaluating Potentialities}

Mountainous areas are a quantitatively and environmentally significant part of the country, occupying $65 \%$ of the total territory of national land, while only $13 \%$ of the total population inhabits these areas. Moreover, mountainous areas appear to have the lowest denseness of population and the highest denseness per $100 \mathrm{~km} 2$ compared with all the country's regions. Respectively, in EU mountainous regions occupy $28 \%$ of its territory, while $8.5 \%$ of the European population inhabits there.

The peculiarity, but also the homogeneity of the problems that are detected in country's mountainous areas, consists of:

1) The traditional spatial composition, as expanded remote - unapproachable zones which historically, due to the geographic relief and the distance from the central developmental axis of the country and the networks of the infrastructure and transportation, have developed defective and peripheral features,

2) As well as the productive reformation that is conduced during the devolvement from the manufacture economies to service economies.

Greek mountain space faces a series of problems of structural nature. These problems are the emanation of both the peculiarity of the Greek natural environment and the social, political, cultural and economical conditions and coincidences that have determined in a large scale specific periods of Greek history.

The splintering off and the enormous dispersion of the unitary proprietorship, treatment and utilization of the land are one of the main features and the most severe structural problems which is dramatically intensified in mountainous regions.

One of the key features and the most serious structural problems dramatically worse in mountainous areas is the fragmentation and dispersal of unit ownership, use, farm land.

Furthermore, the rate of watered agricultural land is low, whereas the average age of the leadership of agricultural development is high (approximately 60\% is more than 55 years old) and their professional education is insufficient.

The terrestrial and climate conditions in the mountainous agriculture are extremely unfavorable (high altitude, intense slopes, poor irrigation, rangeland suitable only for goats, short growing season).
As far as the zoological units of the country are concerned, approximately $32 \%$ is located in mountain areas and their zoological funds is characterized by the higher rate of zoological units (ZU) per farming (4.52) compared with 3.44 $\mathrm{ZU}$ per farming which is the number given for the total of the country. But these numbers given by the NSSG (National Statistical Service of Greece) reveal that the zoological units are gradually reducing in number, despite the fact that the mountainous areas of mainland Greece continue to concentrate half of the goat population and $1 / 3$ of sheep population throughout the country.

The relationship among agriculture, stockbreeding and forestry in mountain areas has always been tight. In the past the phenomenon of deforestation intending to agricultural utilization had emerged, resulting to the small size of farming, located in slopes with relatively big slope and aptitude being utilized. Currently the gradual abandonment of the traditional way for ruminant breeding and more specifically the abandonment of the nomadic way for breeding and the consequent limitation of the stock transportation, result to the reducing of forage capacity of the mountainous rangelands and meadows, the increase of forest fires and severe problems of territorial erosion [9].

In Greece there are five forest vegetation zones, three of which are related with the mountainous space. They are as follows Center of Planning and Economic Research:

1) Beech - fir forest zones and mountainous Para Mediterranean conifer (mountainous, hypo-alpine): This zone is spread on the mountainous areas of mainland Greece, in Peloponnesus as well as on Central and Northern Greece. The predominant species are the hybridogenic fir and the beech. Mixed forests of fir and beech are formed as well as immiscible beech forests that reach the forest limits $(1,800-1,900 \mathrm{~m})$.

2) Psychrovion conifer zone (mountainous - hypo-alpine): This zone appears on the high mountains of northern Greece and consists of psychrovion conifers. We can also observe here forest pine forests, of red and white fir.

3) Out forest zone of high mountains: This zone appears in the high mountains of our country, above forests and forest limits (pseudo-alpine lands). It is composed by underbrush and main vegetation, with scattered small bushes.

Greek forests are much more limited in their extent compared with what they used to be and vegetate mostly in remote mountain areas with intense slopes and degraded terrain.

The classification and distribution of forest products is done in brief categories (classification of few products) and with tardiness between woodcutting and first process in the factory. Lack of mutual information, communication and coordination between forest inspections and industries-factories (market) as well as the intervention of many bureaucratic procedures in distribution of the products sharpen the problem and leads often in the degradation of the products.

Avocation with forestry is a task work and offers lower average of wage compared with other activities. As an unavoidable consequence, the number of occupied with forestry has been reduced at $31 \%$ during the last decade. Even 
though it is not possible for someone to express the opinion that the disadvantageous features of the mountain space have disappeared, there are still some developments visible, especially since 2006 onwards, regarding the peripheral development of this space which composes a basis for new policies.

More specifically:

1) Projects on identifying, recording and characterization of the significant parts of cultural and natural heritage as preservable have been launched by relevant authorities. Models for protection and elevation of these parts have been formed and applied, i.e.: conversion of traditional buildings to hostels, rehabilitation of urban historical centers, organization of woodlands and biotopes pleasant for someone to visit, establishment of rural tourist cooperatives and units, establishment of various museums, organization of spaces for traditional and contemporary cultural events, transformation of preserved buildings and piles to community centers etc.

2) Studies on zoning problems of cultural and mountainous space in total have been elaborated, as well as on the regional agricultural economies, linked also with the surveys of peripheral spaces (in twelve peripheries of the country) which focus especially on the mountainous regions of each periphery.

3) Space-functional - developmental settlement clusters have been institutionalized (Regional Councils Kapodistrias), as an important basis for a complete development of the rural space.

4) A broad transportation and communication network in these regions has been developed and technologies appropriate for inapproachable areas have been forwarded, which contribute to the abolition of isolation, along with the rapid development of citizens' mobility via their own vehicles.

5) Finally, the local self-government of the mountainous areas has been activated with improved educational level and more mature quest and utilization of public and private resources available for regional development, along with EU resources.

All the above details can provide us a concise picture of the Greek mountainous space, as well as the problems that emerge in these areas.

It should be highlighted that the activities until today have some positive effects, yet lacks of overall zoning platform around the national and peripheral space.

Besides, as far as the planning and administrating authorities are concerned, the observed fragmentation causes problems both on the effective introduction of the spatial constituent and the integrated and the multi-sectorial development of the mountainous volumes.

\section{B. Strategic Directions and Policy Measures}

The strategic directions on the integrated development of mountainous regions and mountainous volumes especially through a specific zoning platform; the obtaining of funds that are according to its natural-functional space; the economical utilization of huge infrastructure projects that rehabilitate on a national level their unequal approachability; the elevation and promotion of the opulent natural and cultural environment; finally, the establishment of new administration authorities for mountain spaces.

More specifically, a framework of general strategic directions of spatial development is described below:

1) Complete development of mountainous volumes (forest, stockbreeding, tourist, cultural and environmental development), elevation and utilization of the regional comparative advantages and in parallel their supplemental correlation with the broader economical-functional space of each region.

2) Ensuring of the terms for overcoming the isolation of mountainous volume.

3) Adjustment of the economy of the mountainous areas with the Communal and International process, with appropriate reformation and modernization of utilization and enterprises and the effective promotion and application of new technologies, the organizational support and motivation.

4) Increase of the attractiveness of mountainous areas as places for obtaining relevant funds, and economical activities implementation, considering also the competitive conditions, the perspectives and proceedings in the European Union and in other countries of imminent and broader environment.

5) Preservation of the landscape, the virgin forests and the forest lands, the environmental peculiarities and the cultural resources as crucial natural advantages that characterize the mountainous volumes.

6) Utilization - activation of the existing authorities of protection and development along with creation of new administrational authorities (self-government, non-governmental organizations etc.) on a corporative basis, intending the unified and integrate administration of the mountainous areas.

The mountainous areas can be classified in three basic types (relatively developed, dynamic with unexploited resources and interior), as follows:

1) Areas with adequate settled population and sustainable economical basis which are based on stockbreeding, forest utilization, tourism and vacations, traditional industry, contiguous economical and social services and the Communal support policies, resulting even to diminishing the problems already mentioned.

2) Areas with significant but decreasing population and sinking economical basis, abandonment of marginal agricultural lands, reducing of stockbreeding in spite of the existence of significant agricultural and environmental resources,

3) Areas with a population almost complete abandonment, with or without the presence of significant agricultural and environmental resources, however with problems of further environmental degradation caused by the soil erosion, forest fires or by not preserving the residential projects and monuments etc.

In a mountainous space development plan the situation and the proceedings, the problems and the potentialities for the development plan, in total but also regionally, and also the effectiveness of the policy applied until today have to be evaluated. There has to be a classification of the mountainous areas, as above and to be highlighted the great historical, 
ecological and aesthetic significance of the mountainous village and to give priority on the appliance of the policy in the framework of five action axes which can be summarized as follows:

Axis 1: Transformation of the agricultural activity emphasizing on the development of appropriate methods and means of cultivation and breeding; the development of systems for quality and authenticity certification, standardization, trading, promotion and publicity in the market; the best possible integrate of products with tourism.

Axis 2: Expansible development of primary forms of tourism by ensuring easy access from the national network, integrated roads with a range of sight-seeing, recreational or athletic activities, information and guidance centers, appropriate equipment and service, accommodation adequacy as part of the environment and high level standards and professionalism.

Axis 3: Cottage industry and home handicraft support, by abolishing the reasons for the isolation and blockade until today and by facilitation with infrastructures and economic motivation, encouragement for new enterprise initiatives, reconciliation of these initiatives with the characteristics of primary production and tourist demand of mountain areas.

Axis 4: Composition of mountainous developmental centers based on towns that are characterized by facile connection with the main road network; potentiality of provision for basic utilities and commercial services for citizens who live not farer than $30 \mathrm{~min}$ away; potentiality of services for support and promotional activities which should be function as hubs for beginning and finishing the historical routes and as for providing facilities.

Axis 5: Potentialities for approaching internal zones at the mountainous centers by ensuring a broad and appropriate network along with the prerequisites for regular preservation, rapid intervention for repairing damages, snowplow etc., so as the access to mountainous center from the zone where they facilitate people to be fluent and successful.

In the framework of sustainable development there are some prominent integrated zoning interventions with range of projects and activities, such as:

1) Protection, rehabilitation, promotion and proper utilization of the natural heritage (national parks, landscape of special natural beauty, wetlands, fauna and flora, geomorphic formations),

2) Protection, rehabilitation, promotion and proper utilization of cultural heritage (monuments of all times, anthropogenic landscapes of particular beauty, traditional settlements, vivid tradition, contemporary particular creation),

3) Development of tourist alternatives to the mass concentration in the beaches, such as skiing, spa, mountainous athletic activities, ecological, cultural, agro tourist,

4) Appropriate development of vegetative, stockbreeding, forest production (organic healthy products, traditional, designated products, usage of renewable sources of energy, saving water resources):

- The inhabitants of the mountainous areas, where the appropriate conditions are available (climate, soil, relief, exposure, relevant tradition etc.) should focus on the cultivation with biological methods of vineyards for quality wines production.

- The usage of more automated methods for milking and milk collection or manufacturing of dairy products (although on a level that wouldn't harm the local and traditional features) could ensure for the inhabitants better and easier working and living conditions and furthermore favorable consequences for their social relationships.

- Moreover, motives for occupation with other activities that are close to mountainous and forest lands should be provided, such as mushroom cultivation, forest fruits etc. Finally, an institutional definition on quality criteria (ISO) should be established in order to appeal to the market demands and ensure higher income for the occupied on this special field.

5) Establishment of legislation for residence of the inhabitants also for special categories who prefer mountain areas as their permanent residence, but also as a second/ vacation residence,

6) Construction of infrastructure, technical and services for the population and their activities,

7) Education, training, tutoring, retutoring,

8) Development of initiatives with activation of the regional human factor, although offered inter locally and voluntarily (inhabitants of urban centers descending from mountainous areas, foreign adorers of the Greek mountainous space, Greeks of diasporas),

9) Institutional-administrative organization, reinforcement of spirit of coordination and corporative relationships,

10) Distributional of national financial resources and providing motivations for attraction of financial resources from the broader public and private sector.

\section{RESULTS AND DISCUSSION}

According to these developmental and spatial policies suggested the significance of zoning as the main tool for a complete and sustainable development of the mountainous space is becoming obvious, as well as the necessity for creating a new type of administration authorities per huge spatial unit of mountainous space. These authorities collaborating with peripheral councils and the local development authorities could contribute effectively on the developmental procedure of mountainous areas.

Finally, there is the crucial question, which the structure of zoning will be. Since zoning of mountainous areas should be occupied, in the framework of an organic and flexible plan for land use, with ensuring the cultivable land, the hydrologic network, forests and forest lands, traditional-cultural heritage and area development in the framework of preserving the compatibility with the environment. According to the above, zoning development of mountainous areas should be consistent of:

1) Geographical position borders and extends of the study area.

2) Description of the existing conditions of the natural or ecological environment. 
- Topographical, edaphically, geologic and petrographic data.

- Flora-fauna - biotopes - climatologic elements.

- Raw material, sanative sources and natural energy resources.

3) Description of the existing conditions of human environment.

- Ownership.

- Population evolvement.

- Economical status.

- Current activities.

4) Description of the existing situation of the artificial environment.

- Service networks, buildings etc.

- Transportation and opening up.

5) Description of the existing condition of the cultural environment.

- Historical - traditional - cultural elements.

6) Potentialities and perspectives for development - targets.

- Pursued developmental type, activities that have to be developed and developmental target.

- Infrastructure works.

- Activities and interventions required for promoting the forest area to a natural, cultural and tourist pole of the country.

7) Works suggestions - land uses.

8) Techno-financial elements.

9) Environmental compatibility control with the environment.

The environmental consequences of the investment plan are evaluated and both activities and interventions necessary for natural environment protection are recommended. The effect of the project is done:

1) On the natural environment.

2) On the human environment.

3) On the artificial environment.

4) On the cultural environment.

5) On the institutional environment.

Developmental works in an area use (negative consequence) or enrich (positive consequence) defined by its environmental resources.

6) Implementation of the development authorities legislative framework.

\section{ACKNOWLEDGMENT}

This research has been co-financed by the European Union (European Social Fund - ESF) and Greek national funds through the Operational Program "Education and Lifelong Learning" of the National Strategic Reference Framework (NSRF) - Research Funding Program: Thales. Investing in knowledge society through the European Social Fund.

\section{REFERENCES}

[1] A. K. Doukas, Forest Constructions and Natural Environment, Giaxoudis Publishing, Greece, Thessaloniki, 2004.

[2] A. K. Doukas and V. C. Drosos, Forest Road Construction and Natural Environment, Tziolas Publications, Greece, Thessaloniki, 2013.
[3] D. Rokos, "Technology, civilization and decentralization. An attempt of integrated overview, approach and analysis of multidimensional relationships, interrelationships and interactions on the level of politics and society," presented at $2^{\text {nd }}$ Interdisciplinary Convergence the National Metsovio Polytechnic School for Metsovo. Technology, Civilization and Decentralization, Metsovo, June 3-6, 1998.

[4] D. Rokos, "Fundamental preconditions for a scheme of viable integrated development. The case of one Greek periphery from theory to practice," presented at the $6^{\text {th }}$ International Panhipirotic Convergence, Igoumenitsa, August 26-29, 1999.

[5] G. Rist, The History of Development, Zed books, London and New York, 1997.

[6] F. J. Schuurman, Beyond the Impasse, Zed books, London and N. Jersey, 1996.

[7] D. Rokos, "Photo interpretation remote sensing," presented at National Metsovio Polytechnic School, Laboratory of Remote Sensing, Athens, 1996.

[8] D. Rokos, "The interdisciplinarity of the integrated approach of the natural and socioeconomic reality," presented at Philosophy, Science and Politics, Ioannina, May 24-27, 1996.

[9] Ministry of Environment, Landplaning and Projects of Public Spaces, The Dynamics of the Mountainous and Problematic Regions in the Framework of General Evolvements and Transformation of Agricultural Space, Spatial Survey, Athens, 2000.

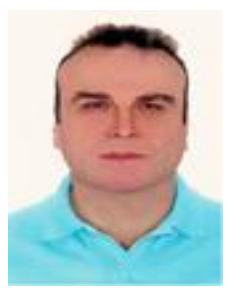

Vasileios C. Drosos was born in Katerini-Pierias Prefecture in Central Macedonia of Greece on May 21, 1965. He was graduated from the Department of Forestry and Natural Environment of Aristotle University of Thessaloniki in 1990 . He is holder a PhD title in "Forest Cadastre" of Department of Forestry and Natural Environment of Aristotle University, Thessaloniki, Greece with degree "Excellent" from 2000. His major field of study is "Surveying and Mapping of Natural Environment".

$\mathrm{He}$ is an associate professor in the Department of Forestry and Management of Environment and Natural Resources in Orestiada, Greece. His current research interests are: Forest technical works, surveying, photogrammetry, environmental standard commitments, technical drawing, forest opening up, skidding and transportation of timber and geoinformation.

Dr. Drosos is member of FORMEC and pan Hellenic society of foresters. He has above 120 publications in Greek and foreigner magazines and congresses.

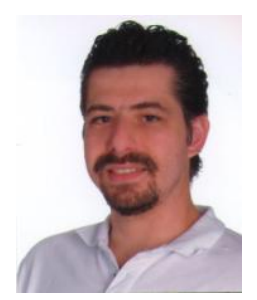

Sarantis-Angelos G. Liampas was born on March 9, 1984 in Thessaloniki of Greece. He graduated from the Department of Forestry and Management of the Environment and Natural Resources of Democritus University of Thrace in Greece. He graduated in 2006. He also holds a master of sustainable management degree of the environment and natural recourses with direction in natural environment mapping and environmental impact assessment studies since 2009.

He worked three years as a forester at forest services in northern Greece and the last three years he works as $\mathrm{PhD}$ candidate in the research funding program: Thales. His major field of study is "Forest Opening Up for timber transport and forest protection".

Mr. Liampas has above 40 publication in Greek and foreigner magazines and congresses.

Dimitrios E. Farmakis was born in Thessaloniki- Thessaloniki Prefecture in Central Macedonia of Greece on July 1, 1970. He was graduated from the Department of Electronic Engineering of Alexandrian Technological Institute of Thessaloniki in 1995. He is holder an MSc title in "Mapping of Natural Environment and Environmental Impacts Assessments of Forest Technical Works" of Department of Forestry and Management of Environment and Natural Resources of Democritus University of Thrace, Orestiada, Greece with degree "Excellent" from 2008. His major field of study is "Surveying and Mapping of Natural Environment".

$\mathrm{He}$ is working as electronic engineering in Thessaloniki.

Mr. Farmakis has above 14 publications in Greek and foreigner magazines and congresses. 